\title{
Laboreal
}

Volume $11 \mathrm{~N}^{\circ} 1$ | 2015

Modos de vida e trabalho

\section{A linguagem e o trabalho : aproximação entre a abordagem ergológica e os estudos da linguagem}

El lenguaje y el trabajo: acercamientos entre el enfoque ergológico y los estudios del lenguaje

Le langage et le travail : rapprochements entre l'approche ergologique et les études du langage

Language and work: an approach between the ergologic point of view and language studies

\section{Cecília Souza-e-Silva e Ana Raquel Motta}

\section{(2) OpenEdition}

\section{Journals}

Edição electrónica

URL: http://journals.openedition.org/laboreal/4501

DOI: $10.4000 /$ laboreal.4501

ISSN: 1646-5237

\section{Editora}

Universidade do Porto

\section{Refêrencia eletrónica}

Cecília Souza-e-Silva e Ana Raquel Motta, « A linguagem e o trabalho : aproximação entre a abordagem ergológica e os estudos da linguagem », Laboreal [Online], Volume 11 NN$^{0} 1$ | 2015, posto online no dia 01 julho 2015, consultado o 08 outubro 2019. URL : http://journals.openedition.org/ laboreal/4501 ; DOI : 10.4000/laboreal.4501

Este documento foi criado de forma automática no dia 8 outubro 2019

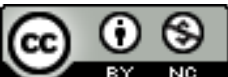

Laboreal está licenciado com uma Licença Creative Commons - Atribuição-NãoComercial 4.0 Internacional. 


\section{A linguagem e o trabalho : aproximação entre a abordagem ergológica e os estudos da linguagem}

El lenguaje y el trabajo: acercamientos entre el enfoque ergológico y los estudios del lenguaje

Le langage et le travail : rapprochements entre l'approche ergologique et les études du langage

Language and work: an approach between the ergologic point of view and language studies

\section{Cecília Souza-e-Silva e Ana Raquel Motta}

\section{REFERÊNCIA}

Artigo original: Souza-E-Silva, C., \& Motta, A.R. (2013). Le langage et le travail Rapprochements entre l'approche ergologique et les études du langage. Ergologia, 9, 179-192.

\section{NOTA DO EDITOR}

http://dx.doi.org/10.15667/laborealxi0115css

1 Desde o princípio, a ergologia, na sua abordagem da complexidade do trabalho humano e suas motivações muitas vezes enigmáticas, mas bem reais, recorre à pluridisciplinaridade, seja em nível dos saberes acadêmicos, seja em nível dos saberes 
que resultam da experiência dos trabalhadores. Em relação à linguagem, lembramos uma entrevista concedida por Schwartz a Durrive e Duc:

Essa competência disciplinar [o trabalho profissional do linguista] é indispensável, nem que seja - justamente - para percebermos os distanciamentos entre as formas relativamente padronizadas da linguagem e aquelas que você mesmo utiliza, para nos darmos conta de que esse distanciamento não é nenhuma fraqueza, mas, ao contrário, um ajustamento inteligente à configuração de sua própria atividade. (Schwartz \& Durrive, 2010, p. 136)

2 Uma das contribuições mais recentes de Schwartz centra-se nos aportes da ergologia à epistemologia. De fato, instaura-se uma nova forma de abordar a questão dos campos, das disciplinas e dos conceitos.

3 Os campos ergológico e epistêmico dizem respeito aos objetos do saber que são estudados seja pelas disciplinas ergológicas, seja pelas disciplinas epistêmicas. $\mathrm{O}$ objeto de estudo no campo epistêmico neutraliza a atividade, os debates de normas, do meio e do momento para conservar somente o resultado, o produto da experiência. $O$ objeto de estudo no campo ergológico está submetido ao debate de normas e não pode ser estudado à revelia do meio e da história.

4 As disciplinas ergológicas e epistêmicas tratam dos métodos, das formas pelas quais são produzidos os conhecimentos, os conceitos. A disciplina epistêmica implica o exercício do pensamento que visa a produzir conhecimentos, e cujo objetivo é neutralizar o meio, as condições históricas, singulares, ligadas ao "aqui-e-agora" da situação de trabalho. A disciplina ergológica implica o reconhecimento da dupla antecipação, a tendência de seguir os debates de normas até a dimensão mais singular da atividade e a confrontação necessária ao meio, à história e a cada situação singular.

5 Em relação aos conceitos, o eixo que parte da disciplina ergológica em direção à disciplina epistêmica apresenta diferentes níveis de epistemicidade que correspondem aos diferentes níveis de integração da atividade humana nos seus respectivos campos de estudo.

Os conceitos da epistemicidade 1 referem-se aos objetos sem atividade, para os quais existe neutralização da história; deixam de lado tudo o que tem relação com os debates das normas e que constitui um acontecimento capaz de produzir algum tipo de efeito sobre estes conceitos. Os conceitos da epistemicidade 2 se constituem pelas normas da vida social cristalizadas em leis, regimentos, procedimentos naquilo que constitui o direito, a autoridade, a organização mais ou menos codificada da vida coletiva. Os conceitos da epistemicidade 3 se caracterizam pela tentativa de explicar as sociedades, suas instituições, suas organizações mais ou menos visíveis. Com um viés explicativo sobre sua gênese, seu funcionamento, a epistemicidade 3 é uma postura de análise dos fatos.

7 Tanto a epistemicidade 2 como a 3 manipulam conceitos pelo mesmo viés na "desaderência" em relação às configurações singulares da atividade. Finalmente, os conceitos da epistemicidade 3 bis, tendencialmente ergológicos, baseiam-se nas normas antecedentes e sempre integram a atividade humana em seu cerne. A espistemicidade 3bis tem como objetivo a observação das variáveis ou renormalizações que acontecem toda vez que uma atividade é posta em prática. Pela própria definição, as epistemicidades, apesar das suas especificidades, caracterizam-se pela manipulação de 
conceitos, portanto de "desaderência" em relação à atividade aqui e agora, excetuando a epistemicidade 3 bis [1].

\section{Lugar híbrido da linguística em relação às epistemicidades}

8 Postulamos que a linguística ocupa um lugar híbrido em relação às epistemicidades, na medida em que ela pode ser considerada ou não através dos debates de normas. Os que não pertencem ao nosso domínio evocam "a" linguística como uma disciplina homogênea, em contrapartida, os que se definem como linguistas encontram grande dificuldade para delimitar a unidade de seu próprio campo, tanto este lhes parece heterogêneo. (Maingueneau, 1988)

9 Nosso ponto de vista será desenvolvido em quatro etapas: fonética articulatória e acústica; estruturalismo; gramática normativa e abordagens enunciativo-discursivas.

\subsection{Fonética articulatória e acústica}

Dois terrenos de estudos se abrem. De um lado, a fonética articulatória que requer conhecimentos de anatomia das cavidades sub-glóticas e da laringe, dos órgãos vocais, do conduto vocal, da produção das consoantes, das vogais, das cartilagens, dos músculos, dos ligamentos, das membranas, etc. Também, é indispensável conhecer o espectro da fala e seus diferentes componentes físicos, com a finalidade de proceder à classificação acústica dos sons da linguagem. De outro lado, o âmbito da fonética acústica, no qual intervêm noções como: movimento periódico, movimento vibratório, frequência, alongamento, ressonador, etc., as quais implicam a utilização de softwares, como o Praat. Estes dois terrenos de estudo estão na epistemicidade 1: aqui os fatores internos da ciência e suas pesquisas em laboratório são privilegiados. Seu escopo é de estudar um objeto, a língua, elaborando protocolos sem considerar aspectos históricos.

11 Um outro tratamento da fonética é possível, aquele que propõe a descrição e análise fonética das produções vocais, colocando-as em relação com uma língua específica, histórica e localizada. Nesse caso, os conceitos procedentes de estudos de laboratório, a epistemicidade 1, são inseridos no contexto mais amplo das atividades humanas e sociais - epistemicidade 3, que operam nas sociedades. Estes estudos são possíveis e desejáveis, e todos os conceitos das ciências humanas e sociais podem eventualmente ser reutilizados pela abordagem ergológica. Fazendo uma comparação, podemos rejeitar que um médico nos trate como se fôssemos um pulmão, e não um ser humano com toda nossa complexidade, mas isto não questiona a existência de estudos do "pulmão" que procuram neutralizar a dimensão do corpo humano submetido aos debates de normas. Tanto para a medicina como para a linguística, os fenômenos assim observados podem ser inscritos nas ciências sociais e humanas a partir de uma abordagem ergológica, isto é, da epistemicidade 3 bis.

\subsection{Estruturalismo}

12 Frente às correntes do século XIX, a posição de Saussure é inovadora porque foi o primeiro a se aventurar numa reflexão teórica sobre a natureza do objeto que constitui a língua e sobre o método pelo qual é possível estudá-la. Em vez de, como muitos de 
seus predecessores, coletar fatos, ele elabora um ponto de vista sobre o objeto, um quadro geral no qual teoriza esses fatos. No entanto o objeto não é dado de início, não se apresenta ao observador ingênuo, ele só é definido após uma reflexão teórica: "Bem longe de dizer que o objeto precede o ponto de vista, diríamos que é o ponto de vista que cria o objeto" (Saussure, 1916/2006, p.15).

13 Nesse sentido, Saussure inaugura a abordagem científica em linguística, isto é, uma reflexão que fornece para si seus próprios conceitos e seus métodos de análise. Encontramos aqui uma fonte central de preocupação para a comunidade científica como um todo, e, portanto, para a linguística saussuriana: "Formuler un principe qui soit fondateur de tout le reste" [2]. Reencontramo-nos aqui com a reflexão de Schwartz sob o princípio de inércia: "Dans l'histoire des idées, ce principe [unités fondamentales de la Phisique] est à la base de tout le reste; c'est un effort prodigieux de la pensée car contre-expérimental" [3] (Schwartz, 2008a).

o sistema linguístico, a língua, é essencialmente um sistema de signos. Esse sistema é concebido por Saussure como uma rede de diferenças entre signos: um signo é, acima de tudo, o que os outros signos não são. $O$ sentido de um signo não corresponde termo a termo ao mundo: na verdade ele está subordinado ao que Saussure, por meio de uma metáfora econômica, chama de "valor", definido como o conjunto das relações que vinculam um signo aos outros signos do sistema. (Maingueneau, 1996) A concepção imanentista do sistema linguístico, isto é, o estudo da língua nela mesma e por ela mesma, deixa de lado toda consideração que não sejam as das relações entre as unidades, exclui do campo da linguística o sujeito de enunciação e o contexto.

Até então, identificamos duas vias utilizadas pela linguística para se aproximar da epistemicidade 1: de uma parte, leva-se em conta unicamente o corpo sem debate de normas (fonética), e, de outra parte, considera-se a língua como um sistema ideal (estruturalismo). Elas se assemelham na tentativa de neutralizar o meio e a história, de "traiter des modèles, des vérités scientifiques qui s'imposent à nous quels que soient les désirs et les débats " [4] (Schwartz, 2009), mas elas divergem no seu modus operandi.

\subsection{Gramática Normativa}

16 A linguagem pode ser estudada, também, pelo viés da gramática normativa, um estudo herdado dos Gregos, mais exatamente dos Alexandrinos, em que o interesse pela língua é inseparável de uma preocupação filológica, e consiste em tornar mais compreensíveis os textos literários prestigiosos e estudar a língua "pura". Trata-se então de um tipo de estudo bem anterior ao surgimento da linguística como ciência. Segundo a gramática normativa, uma ou algumas variáveis linguísticas são tomadas como modelos de comportamento da linguagem, ditando o que é "verdadeiro" ou "falso" segundo o juízo de valor dos grupos sociais. Entramos então no campo da normalização da sociedade, isto é, do que "deve ser", das normas sociais. Aqui, é possível também estabelecer um paralelo entre as epistemicidades e os estudos da linguagem. Voltaremos a isto.

17 Certamente não podemos considerar a gramática normativa como equivalente em cientificidade à fonética nem a outros domínios abordados aqui. Entretanto não podemos negar que ela faz parte dos estudos da linguagem na medida em que é um dos espaços no qual se constrói o conhecimento da língua. A norma, como filtro social do sistema, é um objeto de poder e de disputas nas sociedades. É ela que impõe certas regras em detrimento de outras, julgadas boas ou ruins, corretas ou incorretas. 
Comparativamente às leis jurídicas ou a outras normas sociais, é comum justificarem-se as normas da gramática normativa por meio de argumentos que evocam sua superioridade estética ou lógica: "É mais 'bonito' dizer assim”; “é mais inteligente expressar isto de tal forma". Portanto, sem pretender afirmar que a gramática normativa assume a força de uma lei jurídica, pensamos que é possível estabelecer um paralelo entre o que consideramos como epistemicidade 2 e este tipo de abordagem da linguagem. De fato, as normas "sont instituées, au contraire d'une loi naturelle qui ne peut pas être changée à moins d'une rupture épistémologique; les normes sont transgressables et objets d'infractions, au contraire d'une loi naturelle qui ne peut logiquement pas être trangressée" [5] (Schwartz, 2008b).

\subsection{Abordagens enunciativo-discursivas}

18 Como vimos anteriormente, o par saussuriano língua-fala institui a linguística como ciência procedendo à exclusão da fala, do sujeito e do contexto. Somente a arquitetura interna da língua é levada em conta e a linguagem como atividade é relegada a um resíduo. Entretanto, as abordagens enunciativas e discursivas contestam essa exclusão, e situam a linguagem como atividade de linguagem entre dois protagonistas enunciador e coenunciador -, através da qual o enunciador se situa em relação ao coenunciador, à sua própria enunciação, ao seu enunciado, ao mundo, aos enunciados passados ou futuros. Essa atividade deixa marcas no enunciado, marcas que os linguistas buscam analisar. Dessa forma, a linguagem não é um simples intermediário que se apaga diante das coisas que ela "representa": há não somente o que é dito, mas o fato de dizê-lo (Maingueneau, 1994).

19 Chegamos então à epistemicidade 3, na qual o objeto de conhecimento é a atividade humana, repleta de normas, de renormalização e de história, mais ou menos visíveis. Baseadas nessa constatação, as abordagens enunciativas e discursivas elaboram princípios e conceitos - tais como enunciação, gêneros de discurso, interdiscurso, ethos, etc. - que permitem compreender/explicar a linguagem nas situações mais diversas. Tal como acontece com outras disciplinas das ciências humanas e sociais, há o risco desses conceitos se tornarem hegemônicos, caso sejam utilizados para tentar antecipar e modelizar os fatos sócio-históricos. Eis a importância da epistemicidade 3bis, que leva em conta os debates de normas - tomadas em uma história que não pode ser aniquilada - e que conduzem a renormalizações.

Enfim ao término do nosso percurso, podemos afirmar que, partilhando de um movimento em um mesmo sentido, a abordagem ergológica, de um lado, postula a necessidade da epistemicidade 3bis e integra a atividade humana em seu cerne, e, de outro lado, os estudos enunciativos e discursivos se baseiam no contato permanente com os acontecimentos discursivos reais, dando espaço a "renormalizações" da linguagem.

21 Porém, tais estudos não se situam na esfera da criatividade individual e singular, nem na esfera do âmbito da fala, mas, sobretudo, na esfera do discurso, que se caracteriza pelos embates históricos e linguísticos, mas não se limita a eles. De fato os estudos discursivos indicam que a língua possui uma ordem que lhe é própria, mas essa ordem funciona segundo um processo discursivo delimitado por uma conjuntura dada. Logo, o sentido não é da ordem da língua, porque provém dos posicionamentos discursivos que, por sua vez, são de natureza sócio-histórica. Assim, embora a língua seja mesma para 
diferentes enunciadores, o sentido daquilo que eles dizem pode não ser o mesmo porque provêm de fatores que não são da ordem da língua considerada como sistema (Possenti, 2004).

\section{Conclusão}

Para concluir, um exemplo da abordagem discursiva em situação de trabalho. Em 2011, uma empresa petroquímica multinacional estabelecida no estado de São Paulo implementa, como consultoria, um curso de redação para os operários da fábrica. Esse curso, segundo o responsável do departamento de recursos humanos, atende a uma demanda feita pelos próprios trabalhadores, cujas novas atribuições exigem que saibam ler e escrever um relatório no momento de troca de turnos, o que era feito oralmente até então. Uma das atividades do curso consiste em escrever uma carta narrando um dia de trabalho, destinada a um dos seguintes interlocutores: um novo funcionário recentemente contratado pela empresa para ocupar a mesma função dos operários, ou, alternativamente, a avó que mora no interior. Depois dessa atividade, segue-se uma leitura em voz alta das cartas e comentários sobre os textos e a experiência vivida para escrevê-los. Um dos operários lê o seguinte trecho da carta destinada a sua avó: "Vovó, trabalho em uma empresa que fabrica veneno". E é interrompido por um de seus colegas: "Você não pode dizer isso. Não devemos dizer 'veneno', mas 'defensivos agrícolas"'. E a resposta é incisiva: "Para minha avó, eu vou falar 'veneno".

Essa situação instaura então um debate em torno da importância de sempre levar em conta o contexto: a quem eu falo, onde, por que, e qual é minha posição em relação ao mundo. Outro ponto importante diz respeito à discussão em torno da reação de 'censura' do colega, que explicitou a voz da norma empresarial, e a reafirmação do operário, indicando que na sua vida privada (diálogo com sua avó), ele não seguiria as prescrições da empresa. Por fim, podemos observar até que ponto a linguagem e, em particular a linguagem em situação de trabalho, é um espaço fortemente exposto a debates de normas, no qual as escolhas, aparentemente em escala do microcosmo, da sintaxe, do léxico, do tom, remete ao movimento da sociedade e da história, na plena realização das renormalizações.

Em uma linguística do sistema, o fato de considerar que o operador escolheu entre dois sinônimos, "veneno" e "defensivos agrícolas", equivaleria a perder a riqueza e a complexidade desse acontecimento. É por isso que acreditamos que a visão discursiva da linguagem e a abordagem ergológica da atividade humana são elementos que nos permitem pensar diferentemente a vida, a atividade e o trabalho.

\section{BIBLIOGRAFIA}

Maingueneau, D. (1996). Aborder la linguistique. Paris : Seuil.

. (1994). L'énonciation en linguistique française. Paris : Hachette. 
(1988). Langue et discours, La linguistique et son double. DRLAV, 39, 20-32.

Possenti, S. (2004). Teoria do discurso: um caso de múltiplas rupturas. In F. Mussalim \& A. C. Bentes (Orgs.) Introdução à Linguística: Fundamentos epistemológicos. (pp. 353-392). São Paulo: Cortez.

Saussure, F. (1916/2006). Curso de linguística geral. Trad. Antônio Chelini et al. São Paulo: Cultrix. Schwartz, Y. (2009). Séminaire épistémologique des M2. Synthèse de la séance 11/06/09. Université d'Aix-Marseille, França.

(2008a). Cours d'épistémologie. Synthèse de la séance 08/12/08. Université d'AixMarseille, França.

(2008b). Cours d'épistémologie. Synthèse de la séance 04/11/08. Université d'AixMarseille, França.

Schwartz, Y. \& Durrive, L. (Orgs.) (2010). Trabalho e ergologia - conversas sobre a atividade humana. Trad. Jussara Brito e Milton Athayde. Niterói: UFF. (2. edição, revista e ampliada).

\section{NOTAS}

1. Partimos desses elementos da ergologia - desenvolvidos através de relatórios de alguns seminários de Master 2 na Universidade de Aix-Marseille, assim como do mini-curso ministrado por Yves Schwartz na PUC/SP em abril 2012 - para aproximá-los da linguística.

2. "Formular um princípio que seja fundador de todo o resto" (tradução nossa).

3. "Na história das ideias, esse princípio [unidades fundamentais da Física] está na base de todo o resto; é um esforço prodigioso do pensamento já que é contra-experimental" (tradução nossa).

4. "tratar dos modelos, das verdades científicas que se impõem a nós independentemente dos desejos e dos debates" (tradução nossa).

5. "são instituídas, ao contrário de uma lei natural que não pode ser mudada exceto no caso de uma ruptura epistemológica; as normas são transgressíveis e objetos de infração, ao contrário de uma lei natural que, logicamente, não pode ser transgredida" (tradução nossa).

\section{RESUMOS}

Uma das contribuições mais recentes de Schwartz, centrada sobre os aportes da ergologia à epistemologia, instaura uma nova maneira de abordar a questão dos campos, das disciplinas e dos conceitos. Sobre o eixo que vai da disciplina ergológica à disciplina epistêmica, há vários níveis de epistemicidade. Postulamos que a linguística ocupa um lugar híbrido em relação a essas epistemicidades. Este ponto de vista será desenvolvido em quatro partes: Fonética Articulatória e Acústica; Estruturalismo; Gramática Normativa e Abordagens Enunciativo-discursivas.

Una de las contribuciones más recientes de Schwartz, asentada sobre los aportes de la ergología a la epistemología, establece una nueva manera de acercarse al tema de los campos, las asignaturas y los conceptos. Sobre el eje que va desde la materia ergológica a la epistémica, hay varios niveles epistemológicos. Planteamos que la lingüística ocupa un lugar híbrido con relación a dichas 
posibilidades epistemológicas. Este punto de vista se desarrollará en cuatro partes: Fonética Articulatoria y Acústica; Estruturalismo; Gramática tradicional y Enfoques Enunciativodiscursivos.

L'une des contributions les plus récentes de Schwartz, centrée sur les apports de l'ergologie à l'épistémologie, instaure une nouvelle manière d'aborder la question des champs, des disciplines et des concepts. Sur l'axe allant de la discipline ergologique à la discipline épistémique, il y a plusieurs niveaux d'épistémicité. Nous postulons que la linguistique occupe une place hybride par rapport à ces épistémicités. Ce point de vue sera développé en quatre parties: Phonétique Articulatoire et Acoustique; Structuralisme; Grammaire Normative et Approches Enonciativesdiscursives.

One of the most recent contributions from Schwartz, focused on the Ergology inputs to Epistemology, establishes a new way to address the issue of fields, disciplines and concepts. Based on the axis covering from the ergological discipline to the epistemic discipline, there are various levels of epistemicity. We postulate that Linguistics occupies a hybrid positioning related to these levels. This point of view will be developed in four parts: Articulatory and Acoustic Phonetics; Structuralism; Normative Grammar; and Discourse-Enunciation Approaches.

\section{ÍNDICE}

Palavras-chave: ergologia, epistemologia, linguística, níveis de epistemicidade

Keywords: ergology, epistemology, linguistics, epistemic levels

Palabras claves: ergología, epistemología, lingüística, niveles epistemológicos

Mots-clés: ergologie, épistémologie, linguistique, niveaux d'épistémicité

\section{AUTORES}

\section{CECÍLIA SOUZA-E-SILVA}

Programa de Pós-graduação em Linguística Aplicada aos Estudos da Linguagem/ CNPq, Pontifícia Universidade Católica de São Paulo, Rua Monte Alegre, 984, Perdizes, São Paulo, Brasil cecilinh@uol.com.br

\section{ANA RAQUEL MOTTA}

Programa de Pós-graduação em Linguística Aplicada aos Estudos da Linguagem/ FAPESP, Pontifícia Universidade Católica de São Paulo, Rua Monte Alegre, 984, Perdizes, São Paulo, Brasil anaraquelms@gmail.com 